PEREIRA, F.H.F.; PUIATTI, M.; MIRANDA, G.V.; SILVA, D.J.H.; FINGER, F.L. Divergência genética entre acessos de taro utilizando caracteres morfoqualitativos de inflorescência. Horticultura Brasileira, Brasília, v. 21, n. 3, p. 520-524, julho-setembro 2003.

\title{
Divergência genética entre acessos de taro utilizando caracteres morfo- qualitativos de inflorescência
}

\author{
Francisco Hevilásio F. Pereira ${ }^{1}$; Mário Puiatti ${ }^{1}$; Glauco V. Miranda ${ }^{1}$; Derly J.H. da Silva ${ }^{1}$; Fernando L. \\ Finger ${ }^{1}$ \\ ${ }^{1 / U F V, ~ D e p t o . ~ F i t o t e c n i a, ~ 36570-000 ~ V i c ̧ o s a-M G ; ~ E-m a i l: ~ m p u i a t t i @ u f v . b r ~}$
}

\begin{abstract}
RESUMO
Avaliou-se a divergência genética de acessos de taro pertencentes ao Banco de Germoplasma de Hortaliças da UFV por meio dos caracteres morfo-qualitativos de inflorescências. $\mathrm{O}$ experimento foi conduzido a campo em Viçosa, de setembro/2000 a julho/2001. Utilizou-se o delineamento experimental de blocos casualizados, com cinco repetições e 36 tratamentos (clones), dos quais apenas 11 acessos (BGH 5920, BGH 5926, BGH 5927, BGH 6087, BGH 6089, BGH 6091, BGH 6093, BGH 6094, BGH 6136, BGH 6306 e BGH 6606) apresentaram florescimento espontâneo, passíveis de serem avaliados. A proporção entre o apêndice estéril e porção masculina foi em média de 1,02 , variando de 0,4 (BGH 6136) a 1,4 (BGH 6087). A inflorescência é circundada por uma espata cuja coloração da parte superior (CL) varia do amarelo claro, com ou sem a presença de manchas vermelhas, ao amarelo alaranjado. A cor da porção inferior da espata, contendo as flores femininas (tubo da inflorescência), varia do verde, com ou sem raias ou manchas escuras a púrpura. A espata, na antese, apresenta-se na forma aplanada (BGH 5920, BGH 5926, BGH 6091, BGH 6093, BGH 6094 e BGH 6306) ou encapuchada (BGH 5927, BGH 6087, BGH 6089, BGH 6136 e BGH 6606), com a porção masculina exposta ou envolta, respectivamente. A cor da haste das inflorescências (pedúnculo) variou do verde claro ao púrpuro, com proporção entre comprimentos do pedúnculo e da inflorescência (PCPI) média de 1,8, variando de 1,1 (BGH 5927) a 2,3 (BGH 6089). As inflorescências saem em número de 1 a 5 por axila foliar (NIAF) e apresentam de 1 a 2 ramalhetes florais por planta (NRFP). Os acessos de taro, agrupados pelo método de Tocher, formaram quatro grupos: I (BGH 5920, BGH 6091, BGH 6093, BGH 6094, BGH 5926, BGH 6606 e BGH 6087), II (BGH 6089 e BGH 6306), III (BGH 6136) e IV (BGH 5927). Com base na dispersão dos últimos componentes principais, as variáveis NRFP, CL, PCPI e NIAF, demonstraram ser de pouca importância para a descrição da variabilidade de inflorescências de taro.
\end{abstract}

Palavras-chave: Colocasia esculenta, florescimento, clone, descritores.

\begin{abstract}
Genetic divergence in taro accesses based on the morphological characteristics of inflorescence

The genetic diversity of taro of the Germoplasm Bank of the Universidade Federal de Viçosa, Brazil, was evaluated, by analyzing morphological and quality characteristics of the inflorescence. Plants were grown from 19/09/00 to 13/07/01. Field plots were arranged in a randomized block design with five replicates containing 36 treatments (clones), in which only 11 accesses (BGH 5920, BGH 5926, BGH 5927, BGH 6087, BGH 6089, BGH 6091, BGH 6093, BGH 6094, BGH 6136, BGH 6306 and BGH 6606) flowered spontaneously. The ratio between sterile appendage and male portion was on average 1.02, varying from 0.4 (BGH 6136) to 1.4 (BGH 6087). The inflorescence is surrounded by a spathe with light yellow color at the upper part (LC), with or without spots of red, or yelloworange color. The bottom portion of the spathe which contains the female flowers (inflorescence tube) varied from green, containing or not strips or spots dark to purple color. At anthesis, the spathe shows flat format (BGH 5920, BGH 5926, BGH 6091, BGH 6093, BGH 6094 and BGH 6306) or hooded (BGH 5927, BGH 6087, BGH 6089 , BGH 6136 and BGH 6606), with the male portion exposed or enclosed, respectively. The color of flower stalk varied from pale green to purplish, and ratio between total and inflorescence stalk length (LSLIR) average was 1.8, varying from 1.1 (BGH 5927) to 2.3 (BGH 6089). Number of inflorescences (NI) ranged from 1 to 5 per leaf axis, composing 1 to 2 floral clusters per plant (NFCP). Based on flower morphology the accesses formed four groups by Tocher method: I (BGH 5920, BGH 6091, BGH 6093, BGH 6094, BGH 5926, BGH 6606 and BGH 6087), II (BGH 6089, BGH 6306), III (BGH 6136) and (BGH 5927). Based on dispersion analysis from the last main components, the variables LC, LSLIR, NI and NFCP, showed little influence on the variability description of the inflorescence.
\end{abstract}

Keywords: Colocasia esculenta, flowering, clone, descriptors.

(Recebido para publicação em 20 de maio de 2002 e aceito em 22 de abril de 2003)

$\mathrm{O}$ taro, Colocasia esculenta (L.) Schott, também conhecido popularmente como inhame no centro-sul do Brasil, é a principal hortaliça da família Araceae (Pedralli et al., 2002). É uma importante olerácea do grupo "hortaliças de raízes, tubérculos e rizomas", cuja importância social e econômica vem crescendo nos trópicos e subtrópicos úmidos. No Brasil, os clones de taro existentes apresentam grande variabilidade morfológica
(Puiatti, 2002), o que permite supor a existência de acentuada diversidade genética. Acredita-se que as novas formas de taro originam-se de mutações de estruturas vegetativas, pois, na natureza, raramente ocorrem sementes férteis, devido à incapacidade de autopolinizar-se e à falta de polinizadores reconhecidamente eficientes (Ivancic, 1995).

O pouco conhecimento sobre a floração do taro tem restringido o me- lhoramento genético da cultura aos métodos de coleta e de avaliação de clones existentes. Recentemente, a exploração intensiva dessa espécie tem demandado cultivares mais produtivas. A hibridação artificial é a principal fonte de variação nos programas de melhoramento tradicional. Entretanto, em taro, o principal fator que limita a clássica hibridação intraespecífica é a irregularidade do florescimento e as anormali- 
dades de estruturas florais, que se intensificam com a aplicação de indutores do florescimento (Ivancic, 1995).

O taro não floresce naturalmente em todas as condições ambientais e épocas de cultivo. As inflorescências desenvolvem somente quando as condições básicas, ambientais e fisiológicas, são satisfeitas plenamente. Em Viçosa, sob condições de calor e umidade elevados, temse observado que alguns acessos de taro pertencentes ao Banco de Germoplasma de Hortaliças florescem espontânea e esporadicamente (Puiatti, 2002).

A caracterização de acessos de taro possibilita a identificação dos clones, o intercâmbio de germoplasma, a determinação da divergência genética e a possível utilização em programas de melhoramento. Várias metodologias que utilizam análises multivariadas podem ser utilizadas para determinação de divergência genética. A maioria dessas metodologias é direcionada para análise de caracteres quantitativos ou caracteres qualitativos binários (ausência e presença). Entretanto, na caracterização de acessos em bancos de germoplasma, geralmente, avaliam-se descritores qualitativos que apresentam várias classes, ou seja, multicategóricos. Em taro, como exemplo temos a cor da lâmina (parte superior da espata) nas inflorescências que pode variar de amarelo-clara, amarelo-alaranjada ou amarela com manchas vermelhas.

Segundo Coimbra et al. (2001), uma das alternativas de análise seria a transformação dessa característica em binária, considerando-se a classe com maior freqüência como presença e as demais como ausência (amarela e não amarela, por exemplo). Entretanto, pode-se observar que existe perda de informações neste tipo de análise. Outra alternativa é a utilização de matrizes de dissimilaridade a partir de dados multicategóricos com posterior análise de agrupamento para se avaliar divergência genética (Coimbra et al., 2001).

$\mathrm{O}$ presente trabalho teve como objetivo caracterizar e avaliar a divergência genética do germoplasma de taro do Banco de Germoplasma de Hortaliças da UFV, por meio de caracteres morfológicos de inflorescências.

\section{MATERIAL E MÉTODOS}

O experimento, para a caracterização morfológica de inflorescências de acessos de taro do Banco de Germoplasma de Hortaliças/UFV, foi conduzido na Horta de Pesquisa/UFV, Viçosa-MG, no período de 19/09/00 a 13/07/01. As condições climáticas, durante esse período, foram: temperatura mínima de 11,70 a 19,52, média de 16,84 a 24,49 e máxima de 24,39 a $32,43^{\circ} \mathrm{C}$; umidade relativa de 73,86 a 87,60\%; Insolação média de 3,07 a 8,61 $\mathrm{h}$ dia $^{-1}$; e precipitação pluvial de $0,20 \mathrm{a}$ 229,0 0 mm mês ${ }^{-1}$. Os tratamentos foram constituídos dos 36 acessos de taro pertencentes ao BGH/UFV (BGH 5913, BGH 5914, BGH 5915, BGH 5916, BGH 5917, BGH 5918, BGH 5920, BGH 5921, BGH 5925, BGH 5926, BGH 5927, BGH 5928, BGH 5929, BGH 5931, BGH 6086, BGH 6087, BGH 6088, BGH 6089, BGH 6091, BGH 6092, BGH 6093, BGH 6094, BGH 6095, BGH 6132, BGH 6136, BGH 6137, BGH 6298, BGH 6306, BGH 6307, BGH 6308, BGH 6315, BGH 6606, BGH 6607, BGH 6708, BGH 6730 e BGH 7006), dos quais somente 11 acessos (BGH 5920, BGH 5926, BGH 5927, BGH 6087, BGH 6089, BGH 6091, BGH 6093, BGH 6094, BGH 6136, BGH 6306 e BGH 6606) apresentaram florescimento espontâneo, portanto, passíveis de serem avaliados.

Os tratamentos foram distribuídos em blocos casualisados, com cinco repetições. As parcelas foram compostas de quatro fileiras de $4 \mathrm{~m}$ de comprimento, espaçadas de $1,0 \times 0,5 \mathrm{~m}$, contendo 32 plantas. As parcelas foram distanciadas, umas das outras, de $2 \mathrm{~m}$ nas laterais e de $1 \mathrm{~m}$ nas extremidades. As medidas, para caracterização morfológica e avaliação da divergência genética, via inflorescências, foram realizadas na antese considerando-se todas as plantas da parcela. A avaliação morfológica foi realizada com base nos descritores para Colocasia (IPGRI, 1999) e os principais caracteres considerados foram:

Proporção entre o apêndice estéril e a porção masculina (PAEPM): avaliada por meio de notas, tomando-se as respectivas dimensões longitudinais, em que: $1<0,2 ; 2=0,2-0,5 ; 3=0,6-1,0$; $4=1,1-1,5$; e $5>1,5$.

Cor da lâmina, referente à parte superior da espata (CL): escala de 1 a 7, observada na parte externa e superior da espata em que: 1 = amarelo claro; 2 = amarelo alaranjado; $3=$ amarelo com manchas verdes ou verde púrpura; $4=$ amarelo com manchas vermelho ou vermelho purpúreo; $5=$ laranja avermelhado; 6 = vermelho; e 7 = púrpura ou púrpura azulada.

Cor do tubo da inflorescência, referente à porção inferior da espata (CTI): escala de 1 a 6 , observada na parte inferior da espata que envolve as flores femininas em que: 1 = verde; $2=$ verde com raias ou listas ou manchas claras (amarelas); 3 = verde com raias ou manchas escuras (vermelha, púrpura ou castanho); 4 = vermelho; 5 = púrpura; e $6=$ amarronzado.

Forma da espata na porção masculina (FE): escala de 1 a 8 , em que: 1 = encapuchada (forma de capuz); 2 = carenada; 3 = aplanada; 4 = Completamente aberta e inclinada; 5 = enrolada para trás; $6=$ sinuosa ou torcida; $7=$ enrolada e sinuosa ou torcida; e $8=$ cerrada e sinuosa ou torcida.

Porção masculina da inflorescência (PMI): escala de 1 a 2 em que: 1 = envolta e 2 = exposta.

Cor da haste da inflorescência (CHI): escala de 1 a 8 em que: $1=$ esbranquiçada (transparente); 2 = amarela; $3=$ alaranjada $; 4=$ verde claro $; 5=$ verde; $6=$ vermelha; $7=$ marrom; e $8=$ púrpura.

Proporção entre os comprimentos do pedúnculo e da inflorescência (PCPI): escala de 1 a 5, tomando as respectivas dimensões longitudinais, em que: $1<0,2 ; 2=0,2-0,5 ; 3=0,6-1,0 ; 4=$ $1,1-1,5$; e $5>1,5$.

Número de inflorescências por axila foliar (NIAF): escala de 1 a 5 em que: $1=$ uma; $2=$ duas; $3=$ três; $4=$ quatro; e $5=$ cinco ou mais inflorescências.

Número de ramalhetes florais por planta (NRFP): escala de 1 a 5 em que: $1=1 ; 2=2-3 ; 3=4-6 ; 4=7-10 ;$ e $5>10$.

A divergência genética (grupos de similaridade genética) foi calculada pela 


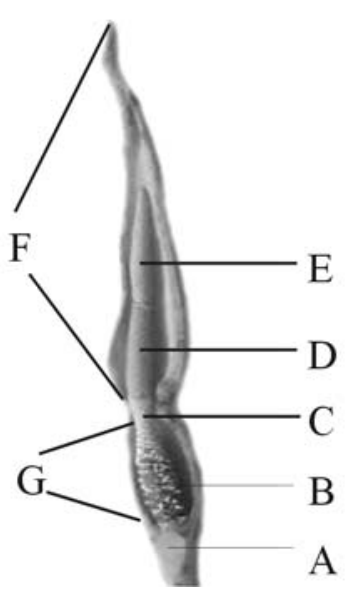

Figura 1. Corte longitudinal da inflorescência de taro mostrando aspectos externos e internos das partes constituintes da espádice: $\mathrm{A}$ pedúnculo, B - flores femininas, C - área de constrição estéril, D - flores masculinas, E ápice estéril, F- lâmina da espata e G tubo da espata. Viçosa, UFV, 2000-01.

análise de agrupamento baseada no Método de Otimização de Tocher, sendo as medidas de dissimilaridade utilizadas obtidas pelo procedimento para dados multicategóricos do programa GENES (Cruz, 2001). Esta metodologia consiste na obtenção de um índice, em que são considerados vários caracteres simultaneamente, sendo que cada caráter pode apresentar várias classes. $\mathrm{O}$ índice leva em consideração a ocorrência e concordâncias de valores. Por exemplo, ao se considerar um caractere com cinco classes, concordâncias entre dois genótipos são: 11, 22, 33, 44 e 55, sendo discordâncias: 12, 13, 14, 15, 21, 23, ..., 54 .

A distância entre os genótipos i e j, não importando o número de caracteres ou classes envolvidas, é dada pela fórmula:

$\mathrm{Dij}=(1-\mathrm{C}) /(\mathrm{C}+\mathrm{D})$, em que:

$\mathrm{C}=$ Concordância de valores; $\mathrm{D}=$ Discordância de valores.

A análise de agrupamento baseada no Método de Otimização de Tocher, tem por objetivo a formação de grupos em que os valores das distâncias intragrupos sejam inferiores a quaisquer distâncias intergrupos. Os grupos formados com a utilização desse método, baseado em descritores qualitativos, apresentam como medida de dissimilaridade variáveis multicategóricas.

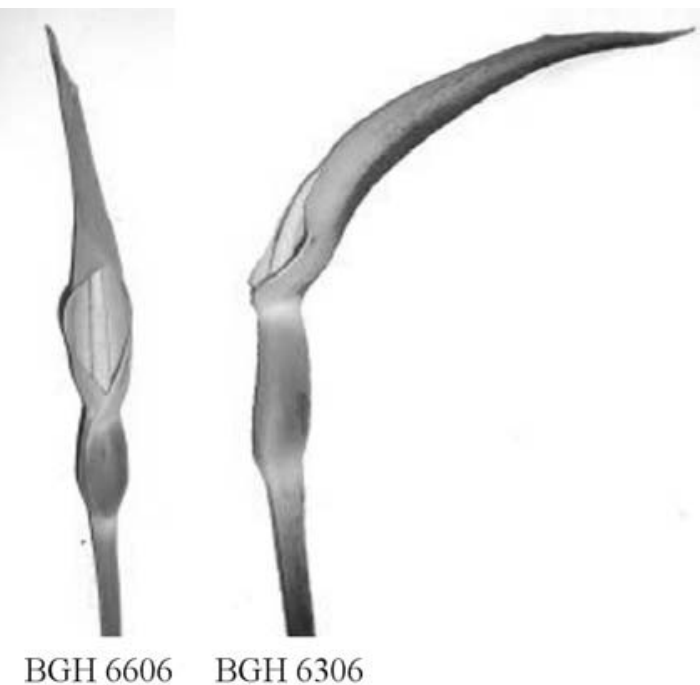

Figura 2. Formato da espata na antese masculina: encapuchada (BGH 6606) e aplanada (BGH 6306). Viçosa, UFV, 2000-01.

Foi realizada a análise de componentes principais a partir de dados padronizados. Para a realização da análise, considera-se que xij é a média padronizada do j-ésimo caráter (variável) $(\mathrm{j}=1,2, \ldots$, v) avaliado no i-ésimo genótipo $(i=1$, $2, \ldots, \mathrm{g})$ e R a matriz de covariâncias ou de correlação entre esses caracteres (ou matriz de correlação fenotípica entre os caracteres utilizando-se os dados originais). A técnica dos componentes principais consiste em transformar o conjunto de v variáveis em novo conjunto, que são funções lineares dos xi's e independentes entre si.

\section{RESULTADOS E DISCUSSÃO}

O início do florescimento ocorreu em 21/01/01, aos 120 dias após o plantio. Dos 11 acessos que floresceram, 10 tiveram o período de florescimento de 97 dias (até 28/04/01) e um acesso (BGH 5927) de 119 dias (20/05/01). Esses resultados foram semelhantes ao encontrados por Pimenta et al. (1994), em dois experimentos com indução hormonal do florescimento de taro conduzidos em casa de vegetação, os quais obtiveram valores de 128 e de 99 dias do plantio ao início da floração e de 150 e 85 dias no período de emissão de flores.

O florescimento foi superior a $10 \%$ nos clones BGH 5920, BGH 5926, BGH
6091, BGH 6093, BGH 6094 e BGH 6306 ; inferiores a $10 \%$ nos clones BGH 5927, BGH 6087, BGH 6089, BGH 6136 e BGH 6606 e ausente nos demais clones.

A inflorescência do taro é em espádice, típica das aráceas, com flores masculinas no ápice e femininas na base, separadas por uma constrição transversa no meio, apresentando apêndice estéril no ápice, em todos os acessos avaliados (Figuras 1 e 2).

A proporção entre o apêndice estéril e porção masculina foi em média de 1,02 , variando de 0,4 (BGH 6136) a 1,4 (BGH 6087). Os acessos BGH 5920 e BGH 6606 apresentaram proporção entre o apêndice estéril e porção masculina, em média, de 1,2; os acessos BGH 6089 e BGH 6306 apresentaram em média 0,7; BGH 6091, BGH 6093 e BGH 6094 apresentaram, em média, 1,1; o acesso BGH 5927 apresentou em média 1,3 e o acesso BGH 5926 apresentou em média 1,0 .

A inflorescência apresenta-se circundada por uma espata cuja coloração da parte superior varia do amarelo-claro, com ou sem a presença de manchas vermelhas, ao amarelo-alaranjado. A cor da porção inferior da espata contendo as flores femininas (tubo da inflorescência) varia de verde, com ou sem raias ou manchas escuras, a púrpura. A cor da haste das inflorescências (pedúnculo) 
Tabela 1. Caracterização morfológica de acessos de taro do BGH/UFV, com base nas características proporção entre apêndice estéril e porção masculina (PAEPM), cor da lâmina (CL), cor do tubo da inflorescência (CTI), forma da espata (FE), porção masculina da inflorescência (PMI), cor da haste da inflorescência (CHI), proporção entre comprimentos do pedúnculo e da inflorescência (PCPI), número de inflorescências/ axila foliar (NIAF) e número de ramalhetes florais/planta (NRFP). Viçosa, UFV, 2000-01.

\begin{tabular}{|c|c|c|c|c|c|c|c|c|c|c|c|c|c|c|c|c|}
\hline \multirow{2}{*}{$\begin{array}{c}\text { Acessos } \\
\text { (BGH) }\end{array}$} & \multicolumn{2}{|c|}{ PAEPM } & \multicolumn{2}{|r|}{$C L$} & \multicolumn{2}{|c|}{ CTI } & \multicolumn{2}{|c|}{$\mathrm{FE}$} & \multicolumn{2}{|c|}{ PMI } & \multicolumn{2}{|c|}{$\mathrm{CHI}$} & \multicolumn{2}{|c|}{ PCPI } & \multirow{2}{*}{$\frac{\text { NIAF }}{V}$} & \multirow{2}{*}{$\frac{\text { NRFP }}{V}$} \\
\hline & $\mathbf{N}$ & V & $\mathbf{N}$ & C & $\mathbf{N}$ & C & $\mathbf{N}$ & C & $\mathbf{N}$ & C & $\mathbf{N}$ & C & $\mathbf{N}$ & $\bar{v}$ & & \\
\hline 5920(I) & 4 & 1,2 & 1 & AC & 1 & $\mathrm{Ve}$ & 3 & $\mathrm{AP}$ & 2 & EXP & 4 & VC & 5 & 1,6 & 3 & 1 \\
\hline 5926(I) & 3 & 1,0 & 1 & $A C$ & 1 & Ve & 3 & $\mathrm{AP}$ & 2 & EXP & 4 & VC & 5 & 1,7 & 2 & 1 \\
\hline 6087(I) & 4 & 1,4 & 1 & $A C$ & 1 & Ve & 1 & ENC & 1 & ENV & 4 & VC & 4 & 1,5 & 5 & 1 \\
\hline 6091(I) & 4 & 1,1 & 1 & $A C$ & 1 & Ve & 3 & $\mathrm{AP}$ & 2 & EXP & 4 & VC & 5 & 2,1 & 3 & 1 \\
\hline 6093(I) & 4 & 1,1 & 1 & $A C$ & 1 & Ve & 3 & $\mathrm{AP}$ & 2 & EXP & 4 & VC & 5 & 1,9 & 3 & 2 \\
\hline 6094(I) & 4 & 1,1 & 1 & $A C$ & 1 & Ve & 3 & AP & 2 & EXP & 4 & VC & 5 & 1,7 & 5 & 1 \\
\hline 6606(I) & 4 & 1,2 & 1 & $A C$ & 1 & Ve & 1 & ENC & 1 & ENV & 4 & VC & 5 & 1,6 & 4 & 1 \\
\hline 6089(II) & 3 & 0,7 & 4 & ACMV & 3 & VME & 1 & ENC & 1 & ENV & 8 & PU & 5 & 2,3 & 5 & 1 \\
\hline 6306(II) & 3 & 0,7 & 4 & ACMV & 3 & VME & 3 & AP & 2 & EXP & 8 & PU & 5 & 1,8 & 2 & 1 \\
\hline 6136(III) & 2 & 0,4 & 2 & $A A$ & 5 & PU & 1 & ENC & 1 & ENV & 8 & PU & 5 & 1,9 & 1 & 1 \\
\hline $5927(\mathrm{IV})$ & 4 & 1,3 & 1 & $A C$ & 1 & $\mathrm{Ve}$ & 1 & ENC & 1 & ENV & 4 & VC & 4 & 1,1 & 4 & 2 \\
\hline
\end{tabular}

*N - nota; C - característica; V - valor médio; AC - amarelo claro; ACMV - amarelo claro com manchas vermelhas; AA - amarelo alaranjado; Ve - verde; VME - verde com manchas escuras; PU - púrpura; AP - aplanada; ENC - encapuchada; EXP - exposta; ENV envolta; VC - verde claro.

variou de verde-claro a púrpura. Os acessos BGH 5920, BGH 5926, BGH 5927, BGH 6087, BGH 6091, BGH 6093, BGH 6094 e BGH 6606 apresentam cor da extremidade da inflorescência (parte superior da espata) amarela-clara, cor do tubo da inflorescência verde e cor da haste da inflorescência verde-clara. Os acessos BGH 6089 e BGH 6306 apresentam cor da extremidade da inflorescência (parte superior da espata) amarela com manchas vermelhas, cor do tubo da inflorescência verde com raias ou manchas escuras e cor da haste da inflorescência púrpura. $\mathrm{O}$ acesso $\mathrm{BGH}$ 6136 apresenta cor da extremidade da inflorescência (parte superior da espata) amarela-alaranjada, cor do tubo da inflorescência púrpura e cor da haste da inflorescência púrpura. A espata, na antese, apresenta-se na forma aplanada (BGH 5920, BGH 5926, BGH 6091, BGH 6093, BGH 6094 e BGH 6306) ou encapuchada (BGH 5927, BGH 6087, BGH 6089, BGH 6136 e BGH 6606), com porção masculina exposta ou envolta, respectivamente (Figura 2).

A proporção entre os comprimentos do pedúnculo e da inflorescência foi, em média, de 1,8, variando de 1,1 (BGH 5927) a 2,3 (BGH 6089). Os acessos BGH 5920 e BGH 6606 apresentaram a proporção entre comprimentos do pedúnculo e da inflorescência, em média, de 1,6; os acessos BGH 5926 e BGH 6094 apresentaram, em média, de 1,7; os acessos BGH 6093 e BGH 6136 apresentaram, em média, de 1,9; os acessos BGH 6087; BGH 6091 e BGH 6306 apresentaram, em média, 1,5; 2,1 e 1,8, respectivamente. As inflorescências saem em número de um (BGH 6136) a 5 (BGH 6087, BGH 6089 e BGH 6094) por axila foliar e apresentam de 1 (BGH 5920, BGH 5926, BGH 6087, BGH 6089, BGH 6091, BGH 6094, BGH 6136, BGH 6306 e BGH 6606) a dois (BGH 5927 e BGH 6093) ramalhetes florais por planta.

Os acessos de taro, com base nos caracteres morfológicos qualitativos, foram agrupados utilizando-se o método de Tocher, a partir da matriz de distâncias entre variáveis multicategóricas, em quatro grupos: I (BGH 5920, BGH 5926, BGH 6087, BGH 6091, BGH 6093, BGH 6094 e BGH 6606), II (BGH 6089 e BGH 6306), III (BGH 6136) e IV (BGH 5927). A dispersão gráfica em relação aos três primeiros componentes principais, que explicam $85,33 \%$ da variação total entre os acessos, foi concordante com os grupos formados pelo método de Tocher. Estes resultados confirmam Cruz \& Regazzi (1997), que re- comendam que os componentes principais devem representar um mínimo de $80 \%$ da variação total, para que seja viável o estudo da divergência genética por meio das distâncias geométricas entre genitores em gráficos de dispersão, cujas coordenadas são escores relativos aos primeiros componentes principais. Além de permitir o estudo da divergência genética por meio das distâncias geométricas entre progenitores em gráficos de dispersão, os componentes principais permitem o descarte daquelas características que contribuíram pouco para a variabilidade genética apresentada entre os acessos. Dessa forma, são descartadas aquelas características que apresentaram o maior coeficiente de ponderação nos componentes principais menos importantes (CP 04; 05; 06; 07; 08 e 09 ), já que juntos contribuíram apenas com $14,67 \%$ da variação total. Com base nesse critério as variáveis NRFP, CL, PCPI e NIAF, podem ser eliminadas, por serem pouco importantes para a descrição da variabilidade da inflorescência dos acessos analisados.

Os acessos com inflorescências do tipo aplanada apresentam maior exposição da espádice, fato que pode favorecer a polinização cruzada pela ação de polinizadores, enquanto que o tipo encapuchada é passível de 
autopolinização. Entretanto, ambos os tipos de inflorescências apresentaram constrição na espata, entre a parte masculina e feminina, o que pode ter impedido a polinização e, conseqüentemente, a fecundação e formação de sementes. Além das barreiras físicas à polinização, mencionadas na literatura e aqui também observadas, Pimenta et al. (1990) verificaram, em teste de germinação de grãos de pólen $(2 \%$ de sacarose $+0,02 \%$ ácido bórico) taxa de germinação menor que $1 \%$ e a viabilidade (carmim acético a $1 \%$ ) entre 30 a $40 \%$ em pólen obtido de plantas que foram induzidas ao florescimento por ácido giberélico exógeno. Todavia, segundo Ivancic (1995), anormalidades de estruturas florais em taro se intensificam com aplicação de indutores do florescimento.

Nos acessos que floresceram, as estruturas florais não progrediram para a formação de frutos, pois entraram em decomposição, provavelmente devido à não polinização e, consequentemente, fecundação das flores femininas e formação de sementes. Dentre os acessos que floresceram, os que apresentaram maior produtividade de rizomas comerciáveis foram BGH 6089 (16,07), BGH $6093(16,34)$ e BGH $6136(15,18)$, sendo que o número de rizomas/planta apresentou-se mais efetivo na estimativa do rendimento, do que propriamente o peso médio (dados não mostrados).

Apesar de apenas 11 acessos, dentre os 36, terem florescido espontaneamente, observou-se grande variabilidade fenotípica de inflorescências dentre esses, indicando ou sugerindo existir variabilidade genética nos clones existentes no BGH/UFV.

\section{AGRADECIMENTOS}

O presente trabalho foi realizado com o apoio do $\mathrm{CNPq}$, referente à bolsa de mestrado concedida ao primeiro autor.

\section{LITERATURA CITADA}

COIMBRA, R.R.; MIRANDA, G.V.; MOREIRA, G.R.; SILVA, D.J.H.; CRUZ, C.D.; CARNEIRO, P.C.S.; SOUZA, L.V.; GUIMARÃES, L.J.M.; MARCASSO, R.C.; CANIATO, F.F. Divergência genética de cultivares de milho baseada em descritores qualitativos. In: SIMPÓSIO DE RECURSOS GENÉTICOS PARAAAMÉRICA LATINA E CARIBE, III SIRGEALC., 2001, Londrina. Anais... Londrina, PR, 2001. p. 266-268.
CRUZ, C.D. Aplicativo computacional em genética e estatística, Viçosa: UFV, 2001, 648 p.

CRUZ, C.D.; REGAZZI, A.J. Modelos biométricos aplicados ao melhoramento genético. 2 ed. Viçosa: UFV, 1997. 390 p.

IPGRI. Descriptors for taro (Colocasia esculenta). International Plant Genetic Resources Institute, Rome, Italy, 1999. 56 p.

IVANCIC,A. Abnormal and unusual inflorescences of taro, Colocasia esculenta (Araceae). Australian Journal Botany, v. 43, p. 475-489, 1995.

PEDRALLI, G.; CARMO, C.A.S.; CEREDA, M.; PUIATTI, M. Uso de nomes populares para as espécies de Araceae e Dioscoreaceae no Brasil. Horticultura Brasileira, Brasília, v. 20, n. 4, p. 530-532, 2002.

PIMENTA, D.S.; CASALI, V.W.D.; REIS F.P. Indução do florescimento no inhame (Colocasia esculenta) com ácido giberélico: aplicação nas gemas dos rizomas de quatro culticares. In: ENCONTRO NACIONAL SOBRE A CULTURA DO INHAME, I., 1987, Viçosa. Anais... Viçosa: UFV, 1994. p. 12-17.

PIMENTA, D.S.; REIS F.P.; CASALI, V.W.D. Melhoramento genético de inhame (Colocasia esculenta (L.) Schott). III - Obtenção de sementes botânicas. In: ENCONTRO NACIONAL SOBRE A CULTURADO INHAME, II., 1989, Dourados. Anais... Campo Grande: UFMG, 1990. p. 103-108.

PUIATTI, M. Manejo da cultura do taro. In: CARMO, C.A.S., (Ed.) Inhame e taro: sistema de produção familiar. Vitória, ES: Incaper, 2002. p. 203-252. 